\title{
Harmonic analysis based on time domain mutual-multiplication window
}

\author{
Tianyuan TAN ${ }^{1}$, Wenjuan CHEN ${ }^{1}$, Kaipei LIU ${ }^{1}$, Niu XIONG ${ }^{1}$, \\ Junmin ZHANG ${ }^{2}$, Junhua WANG ${ }^{1}$
}

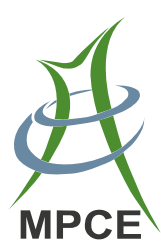

\begin{abstract}
The signal spectral leakage and fence effect are prone to take place during the power harmonic analysis by fast fourier transform (FFT) under asynchronous sampling. The inhibiting ability of classical window functions is restricted by side-lobe behaviors. A new type window function called time domain mutual-multiplication window, is obtained by multiplication operation of several window functions. A novel approach of harmonic analysis is developed through analyzing performances of main-lobe and side-lobe of the new window. Simulation results show that the time domain mutual-multiplication window can significantly suppress frequency spectral leakage and improve the accuracy of harmonic parameter estimation.
\end{abstract}

CrossCheck date: 23 November 2015

Received: 31 July 2015/Accepted: 2 November 2015/Published online: 19 January 2016

(C) The Author(s) 2016. This article is published with open access at Springerlink.com

$\triangle$ Wenjuan CHEN

960572116@qq.com

Tianyuan TAN

tty@whu.edu.cn

Kaipei LIU

kpliu@whu.edu.cn

Niu XIONG

45370523@qq.com

Junmin ZHANG

173902815@qq.com

Junhua WANG

junhuawang@whu.edu.cn

1 School of Electrical Engineering, Wuhan University, Wuhan 430072, China

2 School of Computer Science, South-Central University for Nationalities, Wuhan 430072, China
Keywords Mutual-multiplication window, Fast Fourier Transform, Harmonic Analysis, Main-lobe, Side-lobe

\section{Introduction}

Accurate calculation of harmonic parameters plays an important role in harmonic source localization, harmonic control and power system stability [1-3]. However, in practical applications, the accuracy of harmonic estimation would be reduced under some situations, especially in cases of fundamental frequency variance and background noise presence. Nowadays, fast fourier transform (FFT) is widely employed in power harmonics and inter-harmonics analysis for its simplicity and availability [4, 5]. However, fixed sampling rates are typical for IEC 61044 as $80 f_{r}$ or $200 f_{r}\left(f_{r}\right.$ is the nominal grid frequency) [6]. Thus, the picket fence effect and spectral leakage are caused mainly by asynchronous sampling of the harmonic signal, which means that the sampling rate is not synchronized with the varying fundamental frequency of the power signal. In recent years, many algorithms have been proposed to reduce the picket fence effect and spectral leakage. The most commonly recognized algorithm is weighted interpolation FFT by using nonrectangular window [7-10] which could significantly suppress the spectral leakage and reduce the picket fence effect to increase the accuracy of the harmonic analysis. Selecting the appropriate window function can effectively suppress the influence of spectral leakage [7]. It is well known that the performance of windowed FFT is mainly determined by the window function [8]. A combination of various window functions are proposed to improve the accuracy of power system harmonic analysis, such as Hanning window, Nuttall window, rectangular self-convolution window, Hanning selfconvolution window and Nuttall self-convolution window 
interpolation FFT algorithm [9-19]. However, all side-lobe characteristics of the above window functions need to be improved particularly in spectrum leakage inhibition.

A new type of window functions: mutual-multiplication window which is obtained by multiplication of several window functions is proposed to meet the requirements of ultrahigh precision harmonic analysis. The characteristics of main-lobe and side-lobe of mutual-multiplication window have been analyzed and the relevant harmonic analysis algorithm is also presented. Simulations pinpoint demonstration and verification to the high accuracy of the algorithm.

\section{Mutual-multiplication window functions}

An ideal window function owns the following characteristics.
1) Narrow main-lobe width
2) Low side-lobe level
3) Rapid roll-off speed of side-lobe

If a window meets all those properties, it can sufficiently reduce the spectral leakage and picket fence effect theoretically. Unfortunately, those three criterions conflict with each other and the key issue in the design of the window is to strike a balance between the side-lobe behaviors and the main-lobe width.

The spectral characteristics of the window function include the main-lobe width (main-lobe width, MLW), side-lobe peak level (peak side-lobe level, PSL) and the side-lobe decay rate (side-lobe roll-off rate, SRR). The narrower the main-lobe width is, the higher the frequency resolution is. The lower the side-lobe level is, the less spectral leakage is. The spectral leakage can be suppressed effectively with faster side-lobe decay rate.

Mutual-multiplication window function can be written as follows:

$w_{m c}(n)=\underbrace{w_{1}\left(n_{1}\right) w_{2}\left(n_{2}\right) \ldots w_{p}\left(n_{p}\right)}_{p}$

where $p$ is the number of windows involved in multiplication, called the order mutual-multiplication window while $w_{p}\left(n_{p}\right)$ is the basic window.

According to the multiplication theorem, the window function multiplication in the time domain is equivalent to the window function convolution in the frequency domain. Therefore the mutual-multiplication frequency $p$-order response is:

$W_{m c}(\omega)=\frac{1}{2 \pi} W_{1}\left(\omega_{1}\right) * W_{2}\left(\omega_{2}\right) * \ldots * W_{p}\left(\omega_{p}\right)$

where $\omega$ is the type of basic window; and $p$ is the order of convolution.

As can be seen from (2), there are three factors determining a mutual-multiplication window. A variety of mutual-multiplication windows can be constructed as different basic window function and the multiplication order can form various window choices.

\subsection{Self-multiplication window function}

Self-multiplication window [19] is a special form of mutual-multiplication window. It is obtained by multiplication of several same type basic window functions operation, which can be written as:

$w_{s m}(n)=\underbrace{w_{1}(n) w_{1}(n) \ldots w_{1}(n)}_{p}$

Taking Hanning window for example, analyze its time domain characters and frequency domain characters under different multiplication order.

Figure 1 shows the time domain characters of Hanning self-multiplication windows and Fig. 2 shows the frequency domain characters. Comparisons of Hanning self-multiplication window characteristics are shown in Table 1.

\subsection{Mutual-multiplication window function}

In this section, a mutual-multiplication window function with different basic windows will be discussed as follows. Comparisons of mutual multiplication window characteristics are shown in Table 2.

$w_{m m}(n)=\underbrace{w_{1}(n) w_{2}(n) \ldots w_{p}(n)}_{p}$

\subsection{Summary}

The general formula of multiplication window:

$w_{m m}(n)=\underbrace{w_{1}\left(n_{1}\right) w_{2}\left(n_{2}\right) \ldots w_{p}\left(n_{p}\right)}_{p}$

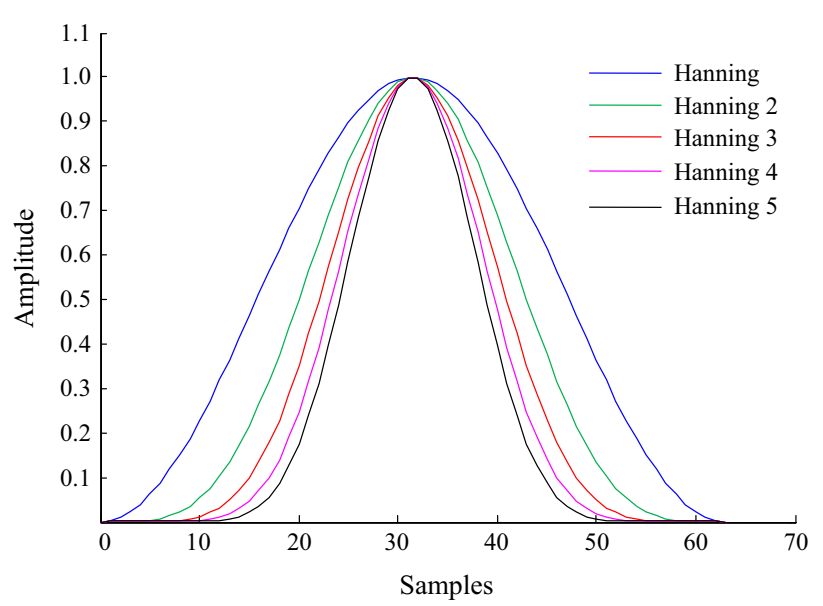

Fig. 1 Time domain characters of Hanning self-multiplication windows 


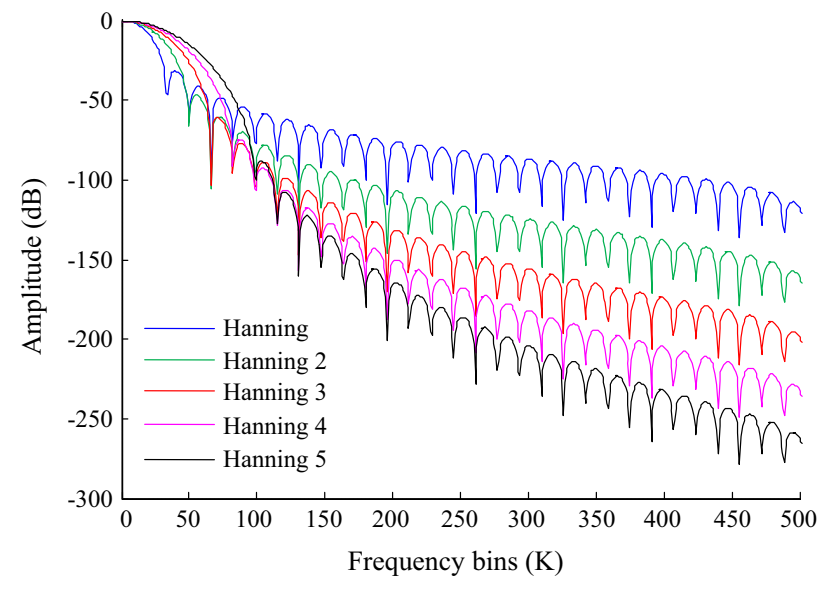

Fig. 2 Normalized logarithm spectrum of Hanning self-multiplication windows

Table 1 Comparisons of Hanning self-multiplication window characteristics with the length of $N=2000$

\begin{tabular}{llll}
\hline Window type & MLW & PSL & SRR \\
\hline Hanning & 0.042969 & -31.5 & 18.04257 \\
Hanning $^{2}$ & 0.058594 & -46.7 & 30.11183 \\
Hanning $^{3}$ & 0.066406 & -60.9 & 41.82431 \\
Hanning $^{4}$ & 0.078125 & -74.6 & 60.22907 \\
Hanning $^{5}$ & 0.085938 & -87.9 & 77.20281 \\
\hline
\end{tabular}

When the basic windows and the lengths of the basic windows are all the same, we get self-multiplication window in section 2.1. When the basic windows are different but the lengths of the basic window are all the same, we get mutual-multiplication window in section 2.2.

Each window function has its own characteristics and can be applied to different applications. To select the right window function, the spectral components of the signal require to be estimated at first. If the measured signal contains many frequency components, a very narrow mainlobe window function needs to be utilized. If it is a singlefrequency signal and higher amplitude accuracy required, it is recommended that the window function with a quite width main-lobe should be considered.

Normally, harmonic components span widely in the frequency domain and a high frequency resolution is not completely required. On the contrary, what practically needed is a better side-lobe performance. Therefore, we can increase the number of items of the window function at the expense of the characteristics of the main-lobe in exchange for better side-lobe characteristics.

Compared with the self-multiplication window, the mutual-multiplication window has two advantages: the
Table 2 Comparisons of mutual multiplication window characteristics with the length of $N=2000$

\begin{tabular}{llcc}
\hline Window type & MLW & PSL & SRR \\
\hline Hann-B & 0.0019531 & -75.3 & 28.7109 \\
Hann2-B & 0.0023193 & -84.4 & 31.6770 \\
Hann-B2 & 0.0024414 & -100.6 & 24.8495 \\
Hann2-B2 & 0.0026855 & -113.4 & 0 \\
Hann-Hamm & 0.0017090 & -49.7 & 17.8547 \\
Hann2-Hamm & 0.0020752 & -62.9 & 29.6265 \\
Hann-Hamm2 & 0.0020752 & -64.4 & 17.7916 \\
Hann2-Hamm2 & 0.0023193 & -77.5 & 29.4670 \\
Hann-RV & 0.0021973 & -105.1 & 17.2414 \\
Hann2-RV & 0.0024414 & -112.5 & 4.5577 \\
Hann-RV2 & 0.0028076 & -140.1 & 18.2944 \\
Hann2-RV2 & 0.0030518 & -153.0 & 0
\end{tabular}

Note: Hann-B is the Hanning and Blackman mutual-multiplication window; Hann2-B is the 2 terms of Hanning and Blackman mutualmultiplication window; Hann-Hamm is Hanning and Hamming mutual-multiplication window; Hann-RV is Hanning and Rife-Vincent mutual-multiplication window, etc

narrower main-lobe width and faster side-lobe roll-off rate. When the window function length is $N$, the side-lobe characteristics of mutual-multiplication windows function are significantly better than that by the classic windows, which could suppress spectral leakage effectively.

\section{Window simulation and implementation}

Setting a signal $x(t)$ whose amplitude is $A$, the initial phase is $\theta$. After the sampling of analog to digital conversion, we obtained the discrete signal:

$x(n)=A \sin \left(\frac{2 \pi n f_{0}}{f_{s}}+\theta\right)$

If the form of window function in time domain is $W(n)$, its continuous spectrum will be $W(2 \pi f)$. Ignoring the negative frequency of the side-lobe, the spectrum function near the positive frequency point can be expressed as:

$X(f)=\left(\frac{A}{2 j}\right)\left[\mathrm{e}^{j \theta} W\left(2 \pi \frac{f-f_{0}}{f_{s}}\right)\right]$

We can get the expression of the discrete Fourier transform of (7):

$X(k \Delta f)=\frac{A}{2 j}\left[\mathrm{e}^{j \theta} W\left(\frac{2 \pi\left(k \Delta f-f_{0}\right)}{f_{s}}\right)\right]$

In (8): the discrete frequency interval is $\Delta f=f_{s} / N, N$ is data truncation length. Actual spectral $f_{0}=k_{0} \Delta f$ is difficult to distribute in the discrete spectrum frequency lines and generally $k_{0}$ is not an integer. 
Reference [11] uses a method of dual-line interpolation. Set the two spectral lines which on the left and right sides of the peak point respectively as $k_{1}$ and $k_{2}$, the amplitude of these two lines to be $y_{1}$ and $y_{2}$ (details shown in Fig. 3 . Reference [11] presents the phase correction formula and amplitude correction formula:

$\theta=\arg \left[X\left(k_{i} \Delta f\right)\right]+\frac{\pi}{2}-\arg \left[W\left(\frac{2 \pi\left(k_{i}-k_{0}\right)}{N}\right)\right]$

$A=\frac{2 y}{\left|W\left(2 \pi \frac{k_{i}-k_{0}}{N}\right)\right|}$

\subsection{Experimental analysis of the signal without noise}

In order to verify the accuracy of the proposed algorithm, the 21st harmonic simulation analysis is conducted in this paper. The signal model is shown as:

$x(n)=\sum_{i=1}^{21} A_{i} \sin \left(\frac{2 \pi f_{1} i n}{f_{s}}+\theta_{i}\right)$

Each harmonic amplitude and harmonic phase is shown in Table 3. The fundamental frequency of the signal $f_{1}=50.1$ $\mathrm{Hz}$. The sampling frequency is $10000 \mathrm{~Hz}$. Data length $N$ of the truncated signal is 2000. Experimental program flow chart is shown in Fig. 4. The input signal $x(n)$ is processed by window function and FFT computation, doublet interpolation window function. The frequency, amplitude, phase for the fundamental and harmonic component can be obtained respectively given the modified formula. The correction formulas of Hanning self-multiplication window and mutual multiplication window are respectively deduced using dual-line interpolation method proposed in this article. The simulation results are given from Tables 4, 5, 6 and 7. As can be seen, the calculation results of mutual-multiplication window are generally better than that of self-multiplication window.

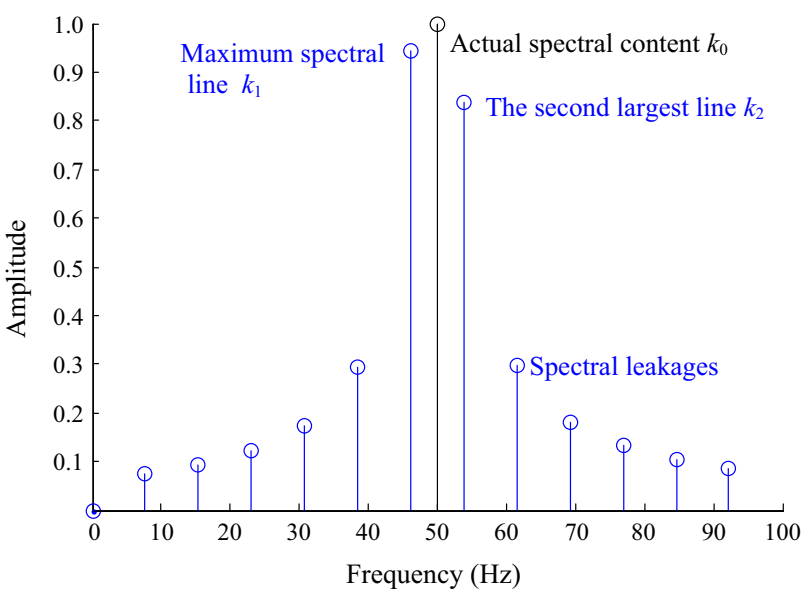

Fig. 3 Frequency spectrum of asynchronous sampling
Table 3 Parameters of the harmonic signals

\begin{tabular}{lll}
\hline Order & Amplitude $(\mathrm{V})$ & Phrase $\left(^{\circ}\right)$ \\
\hline 1 & 220 & 50 \\
2 & 4.4 & 39 \\
3 & 10 & 60.5 \\
4 & 3 & 123 \\
5 & 6 & -52.7 \\
6 & 2.1 & 146 \\
7 & 3.2 & 97 \\
8 & 1.9 & 56 \\
9 & 2.3 & 43.1 \\
10 & 0.8 & -19 \\
11 & 1.1 & 4.1 \\
12 & 0.7 & 40 \\
13 & 0.85 & 10.5 \\
14 & 0.1 & 115 \\
15 & 1 & 25 \\
16 & 0.06 & 53.1 \\
17 & 0.4 & -132 \\
18 & 0.04 & 85 \\
19 & 0.3 & 0.8 \\
20 & 0.005 & 53 \\
21 & 0.01 & -72 \\
\hline
\end{tabular}

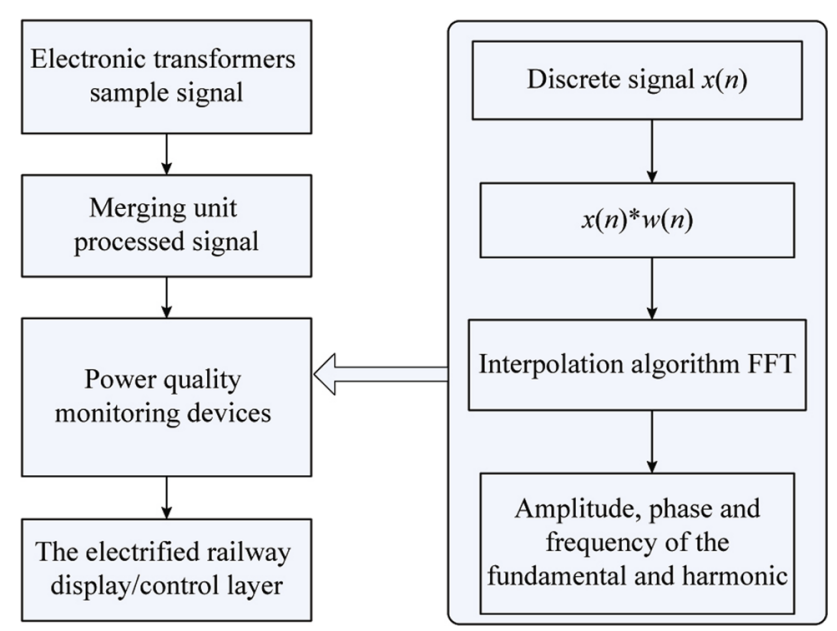

Fig. 4 Flow chart of harmonic analysis

\subsection{Experimental analysis under frequency fluctuations with noise}

In the power system, the maximum frequency deviation range is $\pm 0.5 \mathrm{~Hz}$. Assuming the fluctuation range of the fundamental frequency is $49.5 \sim 50.5 \mathrm{~Hz}$ in (11) and the step interval is $0.1 \mathrm{~Hz}$. Set Gauss noise to be background 
Table 4 Comparisons of relative errors in calculating amplitude using Hanning self-multiplication window

\begin{tabular}{llllll}
\hline Order & Hanning & Hanning2 & Hanning3 & Hanning4 & Hanning \\
\hline 1 & $3.16 \mathrm{E}-06$ & $1.86 \mathrm{E}-06$ & $7.59 \mathrm{E}-07$ & $3.69 \mathrm{E}-07$ & $2.09 \mathrm{E}-07$ \\
2 & $3.09 \mathrm{E}-03$ & $1.37 \mathrm{E}-04$ & $1.50 \mathrm{E}-05$ & $2.89 \mathrm{E}-06$ & $1.16 \mathrm{E}-06$ \\
3 & $1.15 \mathrm{E}-04$ & $3.17 \mathrm{E}-06$ & $1.37 \mathrm{E}-07$ & $1.99 \mathrm{E}-07$ & $7.46 \mathrm{E}-08$ \\
4 & $5.66 \mathrm{E}-06$ & $4.37 \mathrm{E}-08$ & $2.12 \mathrm{E}-07$ & $7.36 \mathrm{E}-08$ & $5.13 \mathrm{E}-08$ \\
5 & $3.42 \mathrm{E}-05$ & $3.36 \mathrm{E}-06$ & $3.33 \mathrm{E}-08$ & $2.41 \mathrm{E}-07$ & $5.03 \mathrm{E}-08$ \\
6 & $1.35 \mathrm{E}-04$ & $3.18 \mathrm{E}-06$ & $9.28 \mathrm{E}-08$ & $1.50 \mathrm{E}-08$ & $2.97 \mathrm{E}-08$ \\
7 & $4.77 \mathrm{E}-05$ & $2.74 \mathrm{E}-06$ & $5.24 \mathrm{E}-08$ & $2.34 \mathrm{E}-07$ & $5.56 \mathrm{E}-08$ \\
8 & $7.24 \mathrm{E}-05$ & $2.87 \mathrm{E}-06$ & $2.03 \mathrm{E}-07$ & $9.58 \mathrm{E}-08$ & $9.61 \mathrm{E}-08$ \\
9 & $1.33 \mathrm{E}-04$ & $2.44 \mathrm{E}-06$ & $1.12 \mathrm{E}-06$ & $3.12 \mathrm{E}-07$ & $2.24 \mathrm{E}-07$ \\
10 & $4.99 \mathrm{E}-04$ & $2.40 \mathrm{E}-05$ & $1.58 \mathrm{E}-05$ & $7.02 \mathrm{E}-06$ & $4.16 \mathrm{E}-06$ \\
11 & $9.02 \mathrm{E}-05$ & $3.09 \mathrm{E}-07$ & $9.22 \mathrm{E}-07$ & $3.44 \mathrm{E}-07$ & $2.15 \mathrm{E}-07$ \\
12 & $5.84 \mathrm{E}-05$ & $2.37 \mathrm{E}-06$ & $2.16 \mathrm{E}-07$ & $1.02 \mathrm{E}-07$ & $9.50 \mathrm{E}-08$ \\
13 & $7.66 \mathrm{E}-05$ & $4.49 \mathrm{E}-06$ & $7.50 \mathrm{E}-08$ & $2.44 \mathrm{E}-07$ & $5.74 \mathrm{E}-08$ \\
14 & $4.01 \mathrm{E}-04$ & $1.73 \mathrm{E}-05$ & $1.72 \mathrm{E}-06$ & $3.09 \mathrm{E}-07$ & $1.06 \mathrm{E}-07$ \\
15 & $8.14 \mathrm{E}-06$ & $5.36 \mathrm{E}-07$ & $3.50 \mathrm{E}-07$ & $1.46 \mathrm{E}-07$ & $9.03 \mathrm{E}-08$ \\
16 & $5.05 \mathrm{E}-04$ & $1.52 \mathrm{E}-05$ & $5.17 \mathrm{E}-07$ & $1.41 \mathrm{E}-07$ & $1.21 \mathrm{E}-07$ \\
17 & $1.09 \mathrm{E}-05$ & $8.49 \mathrm{E}-07$ & $3.54 \mathrm{E}-07$ & $1.50 \mathrm{E}-07$ & $9.34 \mathrm{E}-08$ \\
18 & $9.61 \mathrm{E}-04$ & $2.93 \mathrm{E}-05$ & $2.72 \mathrm{E}-06$ & $2.31 \mathrm{E}-07$ & $1.84 \mathrm{E}-07$ \\
19 & $6.54 \mathrm{E}-07$ & $1.89 \mathrm{E}-06$ & $7.69 \mathrm{E}-07$ & $3.67 \mathrm{E}-07$ & $2.17 \mathrm{E}-07$ \\
20 & $5.77 \mathrm{E}-04$ & $4.04 \mathrm{E}-05$ & $2.22 \mathrm{E}-05$ & $5.84 \mathrm{E}-06$ & $3.98 \mathrm{E}-06$ \\
21 & $5.89 \mathrm{E}-04$ & $4.03 \mathrm{E}-07$ & $8.06 \mathrm{E}-07$ & $3.69 \mathrm{E}-07$ & $5.60 \mathrm{E}-07$ \\
\hline & & & & &
\end{tabular}

Table 5 Comparisons of relative errors in calculating amplitude using Hanning and Blackman mutual-multiplication window

\begin{tabular}{lllll}
\hline Order & Hann-B & Hann2-B & Hann-B2 & Hann2-B2 \\
\hline 1 & $1.38 \mathrm{E}-06$ & $5.65 \mathrm{E}-07$ & $4.15 \mathrm{E}-07$ & $2.19 \mathrm{E}-07$ \\
2 & $4.62 \mathrm{E}-05$ & $4.11 \mathrm{E}-06$ & $1.35 \mathrm{E}-06$ & $1.12 \mathrm{E}-07$ \\
3 & $1.43 \mathrm{E}-06$ & $1.93 \mathrm{E}-07$ & $1.63 \mathrm{E}-07$ & $9.70 \mathrm{E}-08$ \\
4 & $1.85 \mathrm{E}-07$ & $3.37 \mathrm{E}-08$ & $1.53 \mathrm{E}-08$ & $1.10 \mathrm{E}-10$ \\
5 & $1.38 \mathrm{E}-06$ & $1.53 \mathrm{E}-07$ & $1.48 \mathrm{E}-07$ & $9.64 \mathrm{E}-08$ \\
6 & $1.31 \mathrm{E}-06$ & $5.07 \mathrm{E}-08$ & $1.10 \mathrm{E}-08$ & $3.45 \mathrm{E}-09$ \\
7 & $1.18 \mathrm{E}-06$ & $1.84 \mathrm{E}-07$ & $1.61 \mathrm{E}-07$ & $9.93 \mathrm{E}-08$ \\
8 & $1.40 \mathrm{E}-06$ & $1.47 \mathrm{E}-07$ & $1.26 \mathrm{E}-07$ & $7.16 \mathrm{E}-08$ \\
9 & $1.63 \mathrm{E}-07$ & $6.71 \mathrm{E}-07$ & $4.49 \mathrm{E}-07$ & $2.16 \mathrm{E}-07$ \\
10 & $2.25 \mathrm{E}-05$ & $1.13 \mathrm{E}-05$ & $8.18 \mathrm{E}-06$ & $4.27 \mathrm{E}-06$ \\
11 & $5.91 \mathrm{E}-07$ & $6.14 \mathrm{E}-07$ & $4.31 \mathrm{E}-07$ & $2.18 \mathrm{E}-07$ \\
12 & $1.19 \mathrm{E}-06$ & $1.57 \mathrm{E}-07$ & $1.29 \mathrm{E}-07$ & $7.20 \mathrm{E}-08$ \\
13 & $1.84 \mathrm{E}-06$ & $1.37 \mathrm{E}-07$ & $1.46 \mathrm{E}-07$ & $9.97 \mathrm{E}-08$ \\
14 & $5.99 \mathrm{E}-06$ & $4.93 \mathrm{E}-07$ & $1.59 \mathrm{E}-07$ & $1.39 \mathrm{E}-08$ \\
15 & $4.99 \mathrm{E}-07$ & $2.43 \mathrm{E}-07$ & $1.75 \mathrm{E}-07$ & $9.05 \mathrm{E}-08$ \\
16 & $6.18 \mathrm{E}-06$ & $3.22 \mathrm{E}-07$ & $1.11 \mathrm{E}-07$ & $1.51 \mathrm{E}-08$ \\
17 & $6.36 \mathrm{E}-07$ & $2.48 \mathrm{E}-07$ & $1.80 \mathrm{E}-07$ & $9.39 \mathrm{E}-08$ \\
18 & $1.04 \mathrm{E}-05$ & $9.59 \mathrm{E}-07$ & $3.81 \mathrm{E}-07$ & $5.31 \mathrm{E}-08$ \\
19 & $1.39 \mathrm{E}-06$ & $5.67 \mathrm{E}-07$ & $4.16 \mathrm{E}-07$ & $2.19 \mathrm{E}-07$ \\
20 & $2.60 \mathrm{E}-07$ & $1.31 \mathrm{E}-05$ & $8.73 \mathrm{E}-06$ & $4.20 \mathrm{E}-06$ \\
21 & $4.90 \mathrm{E}-07$ & $5.82 \mathrm{E}-07$ & $4.22 \mathrm{E}-07$ & $2.19 \mathrm{E}-07$ \\
\hline & & & &
\end{tabular}

Table 6 Comparisons of relative errors in calculating amplitude using Hanning and Hamm mutual-multiplication window

\begin{tabular}{lllll}
\hline Order & $\begin{array}{l}\text { Hann- } \\
\text { Hamm }\end{array}$ & $\begin{array}{l}\text { Hann } \\
\text { 2-Hamm }\end{array}$ & $\begin{array}{l}\text { Hann-Hamm } \\
2\end{array}$ & $\begin{array}{l}\text { Hann2-Hamm } \\
2\end{array}$ \\
\hline 1 & $2.30 \mathrm{E}-06$ & $9.08 \mathrm{E}-07$ & $1.09 \mathrm{E}-06$ & $4.73 \mathrm{E}-07$ \\
2 & $1.98 \mathrm{E}-09$ & $6.05 \mathrm{E}-07$ & $1.97 \mathrm{E}-05$ & $1.10 \mathrm{E}-06$ \\
3 & $9.18 \mathrm{E}-06$ & $4.42 \mathrm{E}-07$ & $4.70 \mathrm{E}-07$ & $2.26 \mathrm{E}-07$ \\
4 & $1.51 \mathrm{E}-06$ & $2.17 \mathrm{E}-07$ & $3.08 \mathrm{E}-08$ & $2.55 \mathrm{E}-08$ \\
5 & $1.94 \mathrm{E}-07$ & $2.98 \mathrm{E}-07$ & $2.73 \mathrm{E}-07$ & $2.34 \mathrm{E}-07$ \\
6 & $1.23 \mathrm{E}-05$ & $2.50 \mathrm{E}-07$ & $9.88 \mathrm{E}-07$ & $5.80 \mathrm{E}-10$ \\
7 & $2.16 \mathrm{E}-06$ & $3.15 \mathrm{E}-07$ & $9.65 \mathrm{E}-08$ & $2.37 \mathrm{E}-07$ \\
8 & $5.80 \mathrm{E}-06$ & $4.96 \mathrm{E}-07$ & $1.12 \mathrm{E}-07$ & $1.46 \mathrm{E}-07$ \\
9 & $1.23 \mathrm{E}-05$ & $8.16 \mathrm{E}-07$ & $1.97 \mathrm{E}-06$ & $4.48 \mathrm{E}-07$ \\
10 & $7.93 \mathrm{E}-05$ & $1.75 \mathrm{E}-05$ & $2.42 \mathrm{E}-05$ & $9.13 \mathrm{E}-06$ \\
11 & $9.60 \mathrm{E}-06$ & $8.47 \mathrm{E}-07$ & $1.73 \mathrm{E}-06$ & $4.60 \mathrm{E}-07$ \\
12 & $4.59 \mathrm{E}-06$ & $4.54 \mathrm{E}-07$ & $2.98 \mathrm{E}-08$ & $1.50 \mathrm{E}-07$ \\
13 & $3.89 \mathrm{E}-06$ & $3.77 \mathrm{E}-07$ & $1.70 \mathrm{E}-08$ & $2.39 \mathrm{E}-07$ \\
14 & $2.87 \mathrm{E}-05$ & $1.02 \mathrm{E}-07$ & $2.72 \mathrm{E}-06$ & $1.20 \mathrm{E}-07$ \\
15 & $1.42 \mathrm{E}-06$ & $3.87 \mathrm{E}-07$ & $5.03 \mathrm{E}-07$ & $1.94 \mathrm{E}-07$ \\
16 & $5.13 \mathrm{E}-05$ & $1.11 \mathrm{E}-06$ & $4.12 \mathrm{E}-06$ & $7.23 \mathrm{E}-08$ \\
17 & $4.38 \mathrm{E}-07$ & $4.23 \mathrm{E}-07$ & $3.53 \mathrm{E}-07$ & $2.01 \mathrm{E}-07$ \\
18 & $7.71 \mathrm{E}-05$ & $3.94 \mathrm{E}-07$ & $7.16 \mathrm{E}-06$ & $1.36 \mathrm{E}-08$ \\
19 & $1.92 \mathrm{E}-06$ & $9.20 \mathrm{E}-07$ & $1.06 \mathrm{E}-06$ & $4.73 \mathrm{E}-07$ \\
20 & $3.21 \mathrm{E}-05$ & $1.71 \mathrm{E}-05$ & $1.94 \mathrm{E}-05$ & $8.65 \mathrm{E}-06$ \\
21 & $6.21 \mathrm{E}-05$ & $7.35 \mathrm{E}-07$ & $6.68 \mathrm{E}-06$ & $4.61 \mathrm{E}-07$ \\
\hline & & & & \\
\hline
\end{tabular}

Table 7 Comparisons of relative errors in calculating amplitude using Hanning and Rife-Vincent mutual-multiplication window

\begin{tabular}{lllll}
\hline Order & Hann-RV & Hann2-RV & Hann-RV2 & Hann2-RV2 \\
\hline 1 & $8.58 \mathrm{E}-07$ & $3.88 \mathrm{E}-07$ & $2.10 \mathrm{E}-07$ & $1.25 \mathrm{E}-07$ \\
2 & $3.08 \mathrm{E}-06$ & $6.90 \mathrm{E}-08$ & $1.31 \mathrm{E}-07$ & $1.91 \mathrm{E}-08$ \\
3 & $4.21 \mathrm{E}-07$ & $1.70 \mathrm{E}-07$ & $8.95 \mathrm{E}-08$ & $5.47 \mathrm{E}-08$ \\
4 & $1.17 \mathrm{E}-07$ & $9.04 \mathrm{E}-09$ & $7.71 \mathrm{E}-09$ & $4.41 \mathrm{E}-09$ \\
5 & $3.94 \mathrm{E}-07$ & $1.72 \mathrm{E}-07$ & $8.49 \mathrm{E}-08$ & $5.50 \mathrm{E}-08$ \\
6 & $1.84 \mathrm{E}-07$ & $6.30 \mathrm{E}-09$ & $6.62 \mathrm{E}-09$ & $3.96 \mathrm{E}-09$ \\
7 & $3.76 \mathrm{E}-07$ & $1.78 \mathrm{E}-07$ & $8.84 \mathrm{E}-08$ & $5.77 \mathrm{E}-08$ \\
8 & $4.34 \mathrm{E}-07$ & $1.17 \mathrm{E}-07$ & $7.20 \mathrm{E}-08$ & $3.52 \mathrm{E}-08$ \\
9 & $7.19 \mathrm{E}-07$ & $3.89 \mathrm{E}-07$ & $2.11 \mathrm{E}-07$ & $1.26 \mathrm{E}-07$ \\
10 & $1.64 \mathrm{E}-05$ & $7.55 \mathrm{E}-06$ & $4.10 \mathrm{E}-06$ & $2.44 \mathrm{E}-06$ \\
11 & $7.92 \mathrm{E}-07$ & $3.88 \mathrm{E}-07$ & $2.10 \mathrm{E}-07$ & $1.25 \mathrm{E}-07$ \\
12 & $4.00 \mathrm{E}-07$ & $1.20 \mathrm{E}-07$ & $7.16 \mathrm{E}-08$ & $3.68 \mathrm{E}-08$ \\
13 & $4.59 \mathrm{E}-07$ & $1.73 \mathrm{E}-07$ & $8.86 \mathrm{E}-08$ & $5.53 \mathrm{E}-08$ \\
14 & $4.72 \mathrm{E}-07$ & $2.17 \mathrm{E}-09$ & $1.06 \mathrm{E}-08$ & $2.39 \mathrm{E}-09$ \\
15 & $3.57 \mathrm{E}-07$ & $1.61 \mathrm{E}-07$ & $8.71 \mathrm{E}-08$ & $5.13 \mathrm{E}-08$ \\
16 & $8.28 \mathrm{E}-07$ & $8.88 \mathrm{E}-08$ & $3.27 \mathrm{E}-09$ & $3.83 \mathrm{E}-08$ \\
17 & $3.81 \mathrm{E}-07$ & $1.66 \mathrm{E}-07$ & $9.06 \mathrm{E}-08$ & $5.29 \mathrm{E}-08$ \\
18 & $6.78 \mathrm{E}-07$ & $1.52 \mathrm{E}-07$ & $7.39 \mathrm{E}-08$ & $5.84 \mathrm{E}-08$ \\
19 & $8.64 \mathrm{E}-07$ & $3.88 \mathrm{E}-07$ & $2.10 \mathrm{E}-07$ & $1.25 \mathrm{E}-07$ \\
20 & $1.37 \mathrm{E}-05$ & $7.52 \mathrm{E}-06$ & $4.12 \mathrm{E}-06$ & $2.43 \mathrm{E}-06$ \\
21 & $1.03 \mathrm{E}-06$ & $3.87 \mathrm{E}-07$ & $2.10 \mathrm{E}-07$ & $1.25 \mathrm{E}-07$ \\
\hline
\end{tabular}




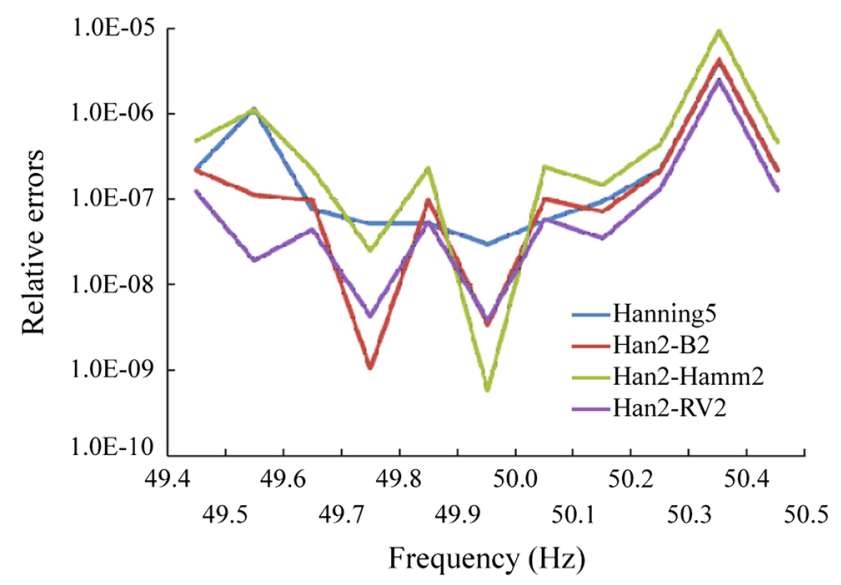

Fig. 5 Harmonic amplitude estimation with the fluctuation of the system frequency

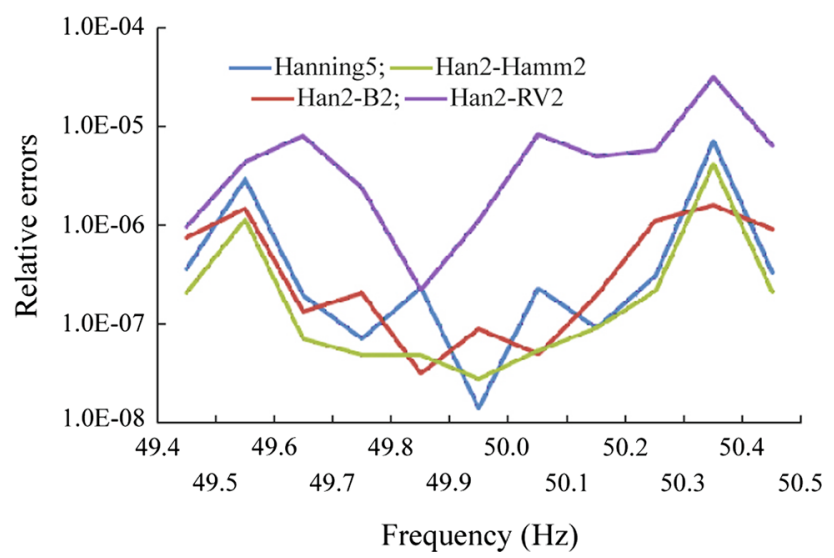

Fig. 6 Harmonic phase estimation with the fluctuation of the system frequency

noise and the noise-signal ratio is $5 \mathrm{~dB}$. The relative error results of amplitude and phase of the fundamental wave are shown in Figs. 5 and 6. It can be seen that the spectral leakage suppression of mutual-multiplication window is stronger. The amplitude relative error maintains at $10^{-8}$ orders. The accuracy of the phase calculation maintains at $10^{-7}$ orders as well.

\section{Conclusion}

In this paper, a completely novel window function is obtained by mutual-multiplication of existing windows. Analysis showed that the new window owns better characteristics, such as twice main-lobe width, lower peak sidelobe level which even lower than the level addition of the two separate window elements and faster roll-off rate which is greater than the addition of two window side-lobe roll-off rate.

In asynchronous sampling, the spectral leakage suppression of mutual-multiplication window is stronger than the classic method. Combined with the improved FFT algorithm, higher accuracy analysis of the harmonic signal can be achieved even in non-steady state. Simulation results verified the correctness and effectiveness of the proposed algorithm. Compared with the existing windowed interpolation algorithm, the newly proposed algorithm significantly improved the calculation accuracy of harmonic parameters.

Open Access This article is distributed under the terms of the Creative Commons Attribution 4.0 International License (http:// creativecommons.org/licenses/by/4.0/), which permits unrestricted use, distribution, and reproduction in any medium, provided you give appropriate credit to the original author(s) and the source, provide a link to the Creative Commons license, and indicate if changes were made.

\section{References}

[1] Wen H, Teng ZS, Wang Y et al (2013) Spectral correction approach based on desirable sidelobe window for harmonic analysis of industrial power system. IEEE Trans Ind Electron 60(3):1001-1010

[2] Stone PEC, Wang JJ, Shin YJ et al (2012) Efficient harmonic filter allocation in an industrial distribution system. IEEE Trans Ind Electron 59(2):740-751

[3] Chang GW, Chen CI, Teng YF (2010) Radial-basis-functionbased neural network for harmonic detection. IEEE Trans Ind Electron 57(6):2171-2179

[4] Lin HC (2012) Power harmonics and interharmonics measurement using recursive group-harmonic power minimizing algorithm. IEEE Trans Ind Electron 59(2):1184-1193

[5] Wen H, Teng ZS, Wang Y et al (2012) Improved windowed interpolation FFT algorithm and application for power harmonic analysis. Trans China Electrotech Soc 27(12):270-276 (in Chinese)

[6] IEC 61000-4-7:2009. Electromagnetic compatibility (EMC)Part 4-7: testing and measurement techniques-general guide on harmonics and interharmonics measurements, and instrumentation for power supply systems and equipment connected thereto

[7] Rodriguez JCC, Lopez JV, Olay CC et al (2010) Dual-tap chopping stabilizer with subcyclic AC soft switching. IEEE Trans Ind Electron 57(9):3060-3074

[8] Salcic Z, Nguang SK, Wu YZ (2009) An improved Taylor method for frequency measurement in power systems. IEEE Trans Instrum Meas 58(9):3288-3294

[9] Barros J, Diego RI (2006) A new method for measurement of harmonic groups in power systems using wavelet analysis in the IEC standard framework. Electr Power Syst Res 76(4):200-208

[10] Kusljevic MD, Tomic JJ, Jovanovic LD (2010) Frequency estimation of three-phase power systems using weighted-leastsquare algorithm and adaptive FIR filtering. IEEE Trans Instrum Meas 59(2):322-329 
[11] Chen CI, Chang GW (2010) Virtual instrumentation and educational platform for time-varying harmonic and interharmonic detection. IEEE Trans Ind Electron 57(10):3334-3342

[12] Reljin IS, Reljin BD, Papic VD (2007) Extremely flat-top windows for harmonic analysis. IEEE Trans Instrum Meas 56(3):1025-1041

[13] Chang GW, Chen CI, Liu YJ et al (2008) Measuring power system harmonics and interharmonics by an improved fast Fourier transform-based algorithm. IET Gener Transm Distrib 2(2):193-201

[14] Testa A, Gallo D, Langella R (2004) On the processing of harmonics and interharmonics: using Hanning window in standard framework. IEEE Trans Power Deliv 19(1):28-34

[15] Jain VK, Collins WL, Davis DC (1979) High-accuracy analog measurements via interpolated FFT. IEEE Trans Instrum Meas 28(2):113-122

[16] Qing BY, Teng ZS, Gao YP et al (2008) An approach for electrical harmonic analysis based on Nuttall window doublespectrum-line interpolation FFT. Proc CSEE 28(25):153-158 (in Chinese)

[17] Zeng B, Teng ZS, Wen H et al (2009) An approach for harmonic analysis based on Rife-Vincent window interpolation FFT. Proc CSEE 29(10):115-120 (in Chinese)

[18] Wen H, Teng ZS, Guo SY et al (2009) Hanning self-convolution window and its application to harmonic analysis. Sci China Ser E 52(2):467-476

[19] Zeng B, Teng ZS (2012) A Nuttall self-convolution windowbased approach to weighted analysis on power system harmonic. Power Syst Technol 35(8):134-139 (in Chinese)
Tianyuan TAN is a Lecturer in School of Electrical Engineering, Wuhan University, China. He received M.S. in automation from Central South University, Changsha, China, and Ph.D. degree in electrical engineering from Tsinghua University, Beijing, China, in 2004 and 2008 respectively. His main interests are power quality analysis and control technology.

Wenjuan CHEN is pursuing her master degree in School of Electrical Engineering, Wuhan University, China. Her research interest includes power quality.

Kaipei LIU is a Professor in School of Electrical Engineering, Wuhan University, China. His research interests include nonlinear control technology and signal processing technology in power electronic system, power quality analysis and control, new energy and smart grid.

Niu XIONG is pursuing his master degree in School of Electrical Engineering, Wuhan University, China. His research interest includes power quality.

Junmin ZHANG is an Associate Professor in School of Computer Science of South-central University for Nationalities, China. Her research interest includes power quality and harmonics suppress.

Junhua WANG is a Professor in School of Electrical Engineering, Wuhan University, China. His research interests include power system and applied electromagnetics. 